\title{
Mixed Type Histology as a Predictive Factor for Esophagojejunostomy Leak in Advanced Gastric Cancer
}

\author{
Karol Rawicz-Pruszyński ${ }^{1, *,+} \mathbb{D}$, Katarzyna Sędłak ${ }^{1,+}{ }^{+} \operatorname{Radosław~Mlak~}^{2} \mathbb{D}$, Jerzy Mielko ${ }^{1}$ and \\ Wojciech P. Polkowski ${ }^{1}$ \\ 1 Department of Surgical Oncology, Medical University of Lublin, Radziwiłłowska 13 St., \\ 20-080 Lublin, Poland; sedlak.katarz@gmail.com (K.S.); jerzy.mielko@umlub.pl (J.M.); \\ wojciech.polkowski@umlub.pl (W.P.P.) \\ 2 Department of Human Physiology, Medical University of Lublin, Radziwiłłowska 11 St., \\ 20-080 Lublin, Poland; radoslaw.mlak@gmail.com \\ * Correspondence: krpruszynski@gmail.com; Tel.: +48-881318964 \\ + These authors contributed equally to this work.
}

Received: 17 June 2020; Accepted: 25 June 2020; Published: 26 June 2020

check for updates

\begin{abstract}
Since esophagojejunostomy leak (EJL) after gastrectomy is a potentially fatal complication and may impact the survival of patients with advanced gastric cancer (GC), it is important to establish risk factors for the EJL and to prevent this surgical complication. The aim of this study was analysis of predictors for the postoperative clinically apparent EJL. All patients operated for advanced GC between October 2016 and December 2019 were analyzed from a prospectively maintained database. The evaluation of the EJL and postoperative complications according to the demographic and clinical (categorized) variables was performed with odds ratio test (multivariate analysis was performed with the use of logistic regression method). Among the 114 patients included in the study, $71.1 \%$ received neoadjuvant chemotherapy and $19.3 \%$ underwent gastrectomy followed by the hyperthermic intraperitoneal chemotherapy (HIPEC). Postoperative EJL was found in 4.6\% patients. The risk of EJL was significantly higher for mixed-type GC (OR = 12.45, 95\% CI: 1.03-150.10; $p=0.0472$ ). The risk of other postoperative complications was significantly higher in patients undergoing HIPEC (OR $=3.88,95 \%$ CI: $1.40-10.80, p=0.0094)$. The number of lymph nodes removed (>38) was characterized by $80 \%$ sensitivity and $79.6 \%$ specificity in predicting EJL (AUC $=0.80$, 95\% CI: $0.72-0.87 ; p<0.0001$ ). Mixed histological type of GC is a tumor-related risk factor for the EJL. HIPEC was confirmed to be a risk factor for postoperative complications after gastrectomy.
\end{abstract}

Keywords: advanced gastric cancer; esophagojejunostomy; postoperative complications

\section{Introduction}

Gastric cancer (GC) is the fifth most frequently diagnosed cancer, with over 1,000,000 new cases and 783,000 deaths in 2018, which makes it the third leading cause of cancer death worldwide [1]. The preferred treatment for advanced, non-metastatic GC is (total) gastrectomy with D2 lymph node dissection. According to the Japanese Gastric Cancer Association, patients with early tumors excluded from endoscopic treatment (cT1N0), can undergo organ-sparing surgery, such as pylorus-preserving gastrectomy and proximal gastrectomy [2]. The type of resection depends mainly on a topographical subsite of GC. In most Asian countries, non-cardia (distal) GC occurs more frequently than cardia (proximal) GC. However, in some Western populations with GC incidence rates lower than the global average, cardia (proximal) GC rates are similar or even higher than distal GC, particularly in men 
(male-to-female ratio 3:1) [3]. The Laurén classification of GC is widely used in clinical practice, since it reflects GC morphology, epidemiology, tumor biology, clinical management and outcome [4].

In Western countries, the standard of care in advanced GC includes perioperative chemotherapy and gastrectomy with D2 lymphadenectomy [5,6]. European studies have shown that advanced GC patients benefit from neoadjuvant chemotherapy compared to those who receive only surgical treatment [7,8]. Moreover, the use of neoadjuvant chemotherapy does not increase the risk of postoperative complications $[9,10]$. Conversion systemic therapy is increasingly used in an oligometastatic setting. If regression is achieved, extended gastrectomy followed by hyperthermic intraperitoneal chemotherapy (HIPEC) is amenable for strictly selected patients with limited peritoneal involvement (P1) or positive cytology (CY1) [11,12].

The extent of the resection determines the preferred reconstruction method [13]. Among numerous restoration techniques, esophagojejunostomy (EJ) is feasible in both, radical (total gastrectomy) and organ-sparing (proximal gastrectomy) gastric surgery. Since for stage IB-III GC radical (total) gastrectomy is recommended, EJ is mostly used as the preferred reconstruction technique [5].

Although the overall rate of complications after total gastrectomy has decreased over the last decade, complications requiring surgical re-intervention remained steady over time [14]. An anastomotic leak, in particular, may significantly increase morbidity and mortality rates $[14,15]$. Postoperative (in-hospital) death after anastomotic leak following total gastrectomy varies from 19 to $62 \%$ [16]. Due to the patient's poor general, cancer-related condition and technical difficulties of the procedure, esophagojejunostomy leak (EJL) remains a critical postoperative condition in both early and advanced GC. The leak rate varies from $5 \%$ to $14 \%$ [17], and it has been considered a poor prognostic factor $[15,17]$.

The EJL risk factors are divided into patient-, tumor-, and surgery-related $[17,18]$. Reported patient-related factors include: age $\geq 65$ years, male gender, anaemia, malnourishment, cardiovascular disease, pulmonary insufficiency, advanced diabetes mellitus, chronic renal failure, smoking, obesity, high visceral fat area, use of steroids and localization and size of the tumor [15,17,19-23]. Tumor-related risk factors include pathological stage IV [21,24] and esophageal invasion [22], whereas risk factors related to surgery are: intraoperative technical errors, prolonged operating time, excessive tension on the anastomosis, limited vascular supply, and combined splenectomy $[17,19,21,25-27]$. The aim of this study was the analysis of predictors for the postoperative, clinically apparent EJL.

\section{Results}

The clinicopathological features of the 114 patients included in the study are shown in Table 1.

Table 1. Clinicopathological variables of all patients included in the study.

\begin{tabular}{cc}
\hline Variable & No. of Patients $n=\mathbf{1 1 4} \mathbf{( \% )}$ \\
\hline Sex & $67(58.8 \%)$ \\
Male & $47(41.2 \%)$ \\
Female & \\
\hline Age (years) & 57.9 \\
Average & 12.5 \\
Standard deviation $( \pm)$ & $58(28-80)$ \\
Median (min-max) & \\
Lauren histological type & $42(37.0 \%)$ \\
Intestinal & $33(28.7 \%)$ \\
Mixed & $39(34.3 \%)$ \\
Diffuse & \\
pT & $5(4.5 \%)$ \\
T0 & $1(0.9 \%)$ \\
T1a & $6(5.4 \%)$ \\
T1b & $17(15.3 \%)$ \\
T2 & $48(42.3 \%)$ \\
T3 & $23(19.8 \%)$ \\
T4a & $14(11.7 \%)$ \\
T4b &
\end{tabular}


Table 1. Cont.

\begin{tabular}{|c|c|}
\hline Variable & No. of Patients $n=114(\%)$ \\
\hline \multicolumn{2}{|l|}{$\mathrm{pN}$} \\
\hline No & $46(40.9 \%)$ \\
\hline N1 & $14(11.8 \%)$ \\
\hline N2 & $20(17.3 \%)$ \\
\hline N3a & $23(20.0 \%)$ \\
\hline N3b & $11(10.0 \%)$ \\
\hline \multicolumn{2}{|l|}{$\mathrm{pM}$} \\
\hline M0 & $84(73.7 \%)$ \\
\hline M1 & $30(26.3 \%)$ \\
\hline \multicolumn{2}{|l|}{ Grading } \\
\hline G1 & $7(3.9 \%)$ \\
\hline G2 & $37(32.4 \%)$ \\
\hline G3 & $69(63.7 \%)$ \\
\hline \multicolumn{2}{|l|}{ Neoadjuvant chemotherapy } \\
\hline Yes & $81(71.1 \%)$ \\
\hline No & $33(28.9 \%)$ \\
\hline \multicolumn{2}{|l|}{ HIPEC } \\
\hline Yes & $22(19.3 \%)$ \\
\hline No & $92(80.7 \%)$ \\
\hline \multicolumn{2}{|l|}{ Surgical margin } \\
\hline R0 & $105(92.2 \%)$ \\
\hline R1 & $9(7.8 \%)$ \\
\hline \multicolumn{2}{|l|}{ Surgical margin $(\mathrm{mm})$} \\
\hline Average & 26 \\
\hline Standard deviation $( \pm)$ & 23 \\
\hline Median (min-max) & $20(5-100)$ \\
\hline \multicolumn{2}{|l|}{ Reconstruction method } \\
\hline TG (Roux-en-Y) & $98(86.0 \%)$ \\
\hline PG+DTR & $16(14.0 \%)$ \\
\hline \multicolumn{2}{|l|}{ Postoperative EJL leak } \\
\hline Yes & $5(4.5 \%)$ \\
\hline No & $109(95.5 \%)$ \\
\hline \multicolumn{2}{|l|}{ Postoperative complications } \\
\hline Yes & $46(40.4 \%)$ \\
\hline No & $68(59.6 \%)$ \\
\hline \multicolumn{2}{|l|}{$\mathrm{CCI}$} \\
\hline Average & 17.4 \\
\hline Standard deviation $( \pm)$ & 26.1 \\
\hline Median (min-max) & $0(0-100)$ \\
\hline \multicolumn{2}{|l|}{ Hospitalization time } \\
\hline Average & 12.9 \\
\hline Standard deviation $( \pm)$ & 8.2 \\
\hline Median (min-max) & $11(4-59)$ \\
\hline \multicolumn{2}{|l|}{ ICU hospitalization time } \\
\hline Average & 6.9 \\
\hline Standard deviation $( \pm)$ & 5.1 \\
\hline Median (min-max) & $5(1-20)$ \\
\hline
\end{tabular}

HIPEC-hyperthermic intraperitonal chemotherapy, EJL-esophagojejunostomy leak, CCI—comprehensive complication index, ICU—intensive care unit, TG—-total gastrectomy, PG—-proximal gastrectomy, DTR—double tract reconstruction.

The intestinal type was the most frequent tumor, followed by diffuse- and mixed-type GC $(37 \%$, $34.3 \%$ and $28.7 \%$ of patients, respectively). There were $42.3 \%$ of patients with pT3, $19.8 \%$ and $11.7 \%$ of patients with pT4a and pT4b tumors, respectively. Lymph node metastases (N1-N3) were present in $59.1 \%$ of patients, and $26.3 \%$ of patients had distant metastases (cM0/pM1). Neoadjuvant chemotherapy was applied in $71.1 \%$ of patients. Gastrectomy with HIPEC procedure was used in $19.3 \%$ of patients. Postoperative complications were reported in $40.4 \%$ of patients. The EJL was found in $5 / 114(4.5 \%)$ patients. The average CCI value was equal to 17.4 (26.1). In patients with or without EJL, the median of CCI was $79.5(58.2-100)$ and $0(0-20.9)$, respectively $(p<0.00001)$. The average time of hospitalization and ICU stay was 12.9 days and 6.9 days, respectively. 


\subsection{EJL Risk Factors}

The risk of the EJL was significantly higher for the mixed type compared to other histological types of GC (OR $=12.45,95 \%$ CI: 1.03-150.10; $p=0.0472$; adjusted). The risk of postoperative complications was significantly higher in patients undergoing HIPEC (OR = 3.88, 95\% CI: 1.40-10.80, $p=0.0094$; adjusted). Univariate and multivariate analyses of the risk of EJL and postoperative complications are presented in Table 2.

\subsection{Comparisons of CCI Values Depending on the Selected Demographic and Clinical Variables}

The CCI was significantly higher in patients with EJL (79.5 vs. 0; $p<0.0001)$ and HIPEC (31.6 vs. $0 ; p=0.0034)$. Differences in the median CCI, depending on demographic, clinical, and pathological features, are presented in Table 3.

\subsection{Comparisons of Selected Demographic and Clinical Variables in Patients with Postoperative Complications}

Significantly longer hospitalization time was observed in patients with EJL (29 vs. 11 days; $p=0.0023)$ and postoperative complications (12.5 vs. 10 days; $p=0.0004)$. Similarly, significantly longer ICU stay was observed in patients with EJL (12 vs. 4 days; $p=0.0071)$. A significantly higher number of harvested lymph nodes was observed in patients with EJL (41 vs. 27; $p=0.0221$ ). Moreover, the number of lymph nodes removed (>38) was characterized by $80 \%$ sensitivity and $79.6 \%$ specificity in predicting EJL (AUC $=0.80,95 \%$ CI: 0.72-0.87; $p<0.0001)$.

\subsection{Correlation between CCI Values and Selected Demographic and Clinical Variables}

Positive correlations were observed between the CCI index and: hospitalization time (rho $=0.300$, $p=0.0017)$ and ICU stay (rho $=0.550, p=0.0223)$.

\subsection{Overall Survival}

In the study group, median OS was 20 months (range: 0.5-114 months; death was reported in $53.1 \%$ of patients). The presence of pT4a or pT4b was associated with an approximately 2 -fold higher risk of shortening the median OS (11 vs. 23 months; $\mathrm{HR}=1.74,95 \% \mathrm{CI}$ : 0.99-3.07; $p=0.0287$ ). The presence of $\mathrm{pN} 1-\mathrm{N} 3$ was associated with an approximately 2.5-fold higher risk of shortening the median OS (11 vs. 63 months; HR = 2.52, 95\% CI: 1.17-5.46; $p=0.0192$; adjusted. The presence of the pM1 was associated with an approximately 4-fold higher risk of shortening the median OS (5 vs. 54 months; HR = 4.16, 95\% CI: 1.88-9.21; $p=0.0005$; adjusted). An increased number of neoadjuvant chemotherapy cycles $(\geq 4)$ was associated with a significantly higher risk of shortening the median OS (6 vs. 23 months; HR = 2.79, 95\% CI: 1.10-7.07; $p=0.0316$; adjusted). Lymph node metastases $(\mathrm{n} \geq 2)$ were associated with a significantly higher risk of shortening the median OS (10 vs. 54 months; $\mathrm{HR}=2.15$, 95\% CI: 1.22-3.79; $p=0.0081$; adjusted). LNR $\geq 0.07$ was associated with a significantly higher risk of shortening the median OS (9 vs. 54 months; HR = 2.44, 95\% CI: 1.38-4,30; $p=0.0022$; adjusted). 
Table 2. Univariate and multivariate analysis of the risk of EJL and postoperative complications.

\begin{tabular}{|c|c|c|c|c|c|c|c|c|}
\hline \multirow{2}{*}{ Variable } & \multicolumn{2}{|c|}{ EJL $n(\%)$} & \multirow{2}{*}{$\begin{array}{c}\text { Univariate } \\
\text { OR }(95 \% \mathrm{CI}) p\end{array}$} & \multirow{2}{*}{$\begin{array}{c}\text { Multivariate } \\
\text { OR }(95 \% \mathrm{CI}) p\end{array}$} & \multicolumn{2}{|c|}{ Postoperative Complications $n(\%)$} & \multirow{2}{*}{$\begin{array}{c}\text { Univariate } \\
\text { OR }(95 \% \mathrm{CI}) p\end{array}$} & \multirow{2}{*}{$\begin{array}{l}\text { Multivariate } \\
\text { OR }(95 \% \mathrm{CI})\end{array}$} \\
\hline & Yes & No & & & Yes & No & & \\
\hline Sex & & & 0.12 & 0.94 & & & 1.00 & 1.30 \\
\hline Male & $5(100 \%)$ & $60(56.07 \%)$ & $(0.01-2.15)$ & $(0.41-2.15)$ & $27(58.7 \%)$ & $40(58.8 \%)$ & $(0.47-2.15)$ & $(0.54-3.12)$ \\
\hline Female & $0(0 \%)$ & $49(43.92 \%)$ & 0.1478 & 0.8894 & $19(41.3 \%)$ & $28(41.2 \%)$ & 0.9891 & 0.5595 \\
\hline Age & & & 0.25 & 0.79 & & & 1.16 & 1.07 \\
\hline$<58$ years & $4(80 \%)$ & $53(49.53 \%)$ & $(0.03-2.27)$ & $(0.45-1.36)$ & $24(52.2 \%)$ & $33(48.5 \%)$ & $(0.55-2.45)$ & $(0.46-2.46)$ \\
\hline$\geq 58$ years & $1(20 \%)$ & $54(50.47 \%)$ & 0.2156 & 0.3919 & $22(47.8 \%)$ & $35(51.5 \%)$ & 0.7027 & 0.8735 \\
\hline Lauren type & & & 11.11 & 12.45 & & & 0.81 & 0.88 \\
\hline Mixed & $4(80 \%)$ & $27(26.47 \%)$ & (1.19-103.86) & $(1.03-150.10)$ & $14(31.1 \%)$ & $17(27.0 \%)$ & $(0.35-1.90)$ & $(0.34-2.81)$ \\
\hline Intestinal, Diffuse & $1(20 \%)$ & $75(73.53 \%)$ & 0.0347 & 0.0472 & $31(68.9 \%)$ & $46(73.0 \%)$ & 0.6404 & 0.7862 \\
\hline Lauren type & & & 0.17 & 0.81 & & & 0.77 & 1.62 \\
\hline Diffuse & $0(0 \%)$ & $36(35.29 \%)$ & $(0.01-3.08)$ & $(0.71-3.48)$ & $17(37.8 \%)$ & $20(31.7 \%)$ & $(0.34-1.71)$ & $(0.65-3.99)$ \\
\hline Intestinal, Mixed & $5(100 \%)$ & $66(64.71 \%)$ & 0.2280 & 0.2634 & $28(62.2 \%)$ & $43(68.3 \%)$ & 0.5153 & 0.3011 \\
\hline Lauren type & & & 0.40 & 0.99 & & & 1.56 & 0.71 \\
\hline Intestinal & $1(20 \%)$ & $39(38.23 \%)$ & $(0.04-3.75)$ & $(0.70-3.42)$ & $14(31.1 \%)$ & $26(41.3 \%)$ & $(0.69-3.48)$ & $(0.29-1.73)$ \\
\hline Mixed, Diffuse & $4(80 \%)$ & $63(61.76 \%)$ & 0.4250 & 0.2811 & $31(68.9 \%)$ & $37(58.7 \%)$ & 0.2824 & 0.4529 \\
\hline Grading & & & 2.78 & 1.46 & $15(35.7 \%)$ & $22(36.7 \%)$ & 0.96 & 1.10 \\
\hline $\mathrm{G} 1, \mathrm{G} 2$ & $3(60 \%)$ & $34(35.05 \%)$ & $(0.44-17.45)$ & $(0.81-4.01)$ & $27(64.3 \%)$ & $38(63.3 \%)$ & $(0.42-2.18)$ & $(0.44-2.78)$ \\
\hline G3 & $2(40 \%)$ & $63(64.95 \%)$ & 0.2755 & 0.1484 & $15(35.7 \%)$ & $22(36.7 \%)$ & 0.9216 & 0.8344 \\
\hline $\mathrm{pT}$ & $3(60 \%)$ & $72(68.57 \%)$ & 0.69 & 0.78 & $30(65.2 \%)$ & $46(70.8 \%)$ & 0.77 & 1.06 \\
\hline $\mathrm{T} 0, \mathrm{~T} 1 \mathrm{a}, \mathrm{T} 1 \mathrm{~b}, \mathrm{~T} 2, \mathrm{~T} 3$ & & & $(0.11-4.31)$ & $(0.08-7.53)$ & & & $(0.34-1.74)$ & $(0.43-2.63)$ \\
\hline T4a, T4b & $2(40 \%)$ & $33(31.43 \%)$ & 0.6892 & 0.8285 & $16(34.8 \%)$ & $19(29.2 \%)$ & 0.5356 & 0.8983 \\
\hline $\mathrm{pN}$ & & & 0.35 & 0.42 & & & 0.88 & 0.93 \\
\hline NO & $1(20 \%)$ & $43(41.35 \%)$ & $(0.04-3.28)$ & $(0.04-4.10)$ & $18(39.1 \%)$ & $27(42.2 \%)$ & $(0.41-1.91)$ & $(0.39-2.18)$ \\
\hline N1a, N2, N3a, N3b & $4(80 \%)$ & $61(58.65 \%)$ & 0.3613 & 0.4532 & $28(60.9 \%)$ & $37(57.8 \%)$ & 0.7478 & 0.8631 \\
\hline $\mathrm{pM}$ & & & 1.49 & 1.42 & $32(69.6 \%)$ & & 0.70 & 0.85 \\
\hline M0 & $4(80 \%)$ & $78(72.90 \%)$ & $(0.16-13.86)$ & $(0.11-18.61)$ & $14(30.4 \%)$ & $52(76.5 \%)$ & $(0.30-1.63)$ & $(0.27-2.43)$ \\
\hline M1 & $1(20 \%)$ & $29(27.10 \%)$ & 0.7275 & 0.7918 & $32(69.6 \%)$ & $16(23.5 \%)$ & 0.4124 & 0.7142 \\
\hline
\end{tabular}


Table 2. Cont.

\begin{tabular}{|c|c|c|c|c|c|c|c|c|}
\hline \multirow{2}{*}{ Variable } & \multicolumn{2}{|c|}{ EJL $n(\%)$} & \multirow{2}{*}{$\begin{array}{c}\text { Univariate } \\
\text { OR }(95 \% \mathrm{CI}) p\end{array}$} & \multirow{2}{*}{$\begin{array}{c}\text { Multivariate } \\
\text { OR }(95 \% \mathrm{CI}) p\end{array}$} & \multicolumn{2}{|c|}{ Postoperative Complications $n(\%)$} & \multirow{2}{*}{$\begin{array}{c}\text { Univariate } \\
\text { OR }(95 \% \mathrm{CI}) p\end{array}$} & \multirow{2}{*}{$\begin{array}{l}\text { Multivariate } \\
\text { OR }(95 \% \mathrm{CI}) p\end{array}$} \\
\hline & Yes & No & & & Yes & No & & \\
\hline Surgical margin & & & 1.44 & 1.11 & & & 0.94 & 0.87 \\
\hline R0 & $5(100 \%)$ & $98(91.6 \%)$ & $(0.07-27.63)$ & $(0.11-11.59)$ & $41(\%)$ & $61(\%)$ & $(0.27-3.17)$ & $(0.24-3.11)$ \\
\hline $\mathrm{R} 1$ & - & $9(8.4 \%)$ & 0.8089 & 0.9308 & $5(\%)$ & $7(\%)$ & 0.9218 & 0.8329 \\
\hline $\begin{array}{c}\text { No. of removed lymph } \\
\text { nodes }\end{array}$ & & & 10.79 & 14.53 & & & 1.70 & 1.44 \\
\hline Yes & $5(100 \%)$ & $52(50.5 \%)$ & $(0.58-200.17)$ & $(1.47-143.73)$ & $27(60 \%)$ & $30(46.9 \%)$ & $(0.78-3.68)$ & $(0.65-3.22)$ \\
\hline No & - & $51(49.5 \%)$ & 0.1104 & 0.9939 & $18(40 \%)$ & $34(53.1 \%)$ & 0.1782 & 0.3673 \\
\hline HIPEC & & & 1.02 & 2.40 & & & 0.30 & 3.88 \\
\hline Yes & $1(20 \%)$ & $21(19.63 \%)$ & $(0.11-9.64)$ & $(0.18-31.86)$ & $32(69.6 \%)$ & $60(88.2 \%)$ & $(0.16-0.80)$ & $(1.40-10.80)$ \\
\hline No & $4(80 \%)$ & $86(80.37 \%)$ & 0.9836 & 0.5074 & $14(30.4 \%)$ & $8(11.8 \%)$ & 0.0162 & 0.0094 \\
\hline Reonstruction method & & & 1.71 & 1.75 & & & 0.85 & 1.39 \\
\hline TG (Roux-en-Y) & $5(100 \%)$ & $93(86.92 \%)$ & $(0.09-32.51)$ & $(0.26-11.63)$ & $39(84.8 \%)$ & $59(86.8 \%)$ & $(0.29-2.47)$ & $(0.41-4.73)$ \\
\hline PG+DTR & $0(0 \%)$ & $14(13.08 \%)$ & 0.7225 & 0.5612 & $7(15.2 \%)$ & $9(13.2 \%)$ & 0.7652 & 0.5969 \\
\hline $\begin{array}{l}\text { Neoadjuvant } \\
\text { chemotherapy }\end{array}$ & & & 4.74 & 4.53 & & & 0.79 & 1.03 \\
\hline No & $0(0 \%)$ & $32(29.91 \%)$ & $(0.25-88.16)$ & $(0.05-5.06)$ & $12(26.1 \%)$ & $21(30.9 \%)$ & $(0.34-1.82)$ & $(0.39-2.66)$ \\
\hline Yes & $5(100 \%)$ & $75(70.09 \%)$ & 0.2973 & 0.1963 & $34(73.9 \%)$ & $47(69.1 \%)$ & 0.5800 & 0.9516 \\
\hline
\end{tabular}

OR—odds ratio, 95\%CI—95\% confidence interval, n/a—not applicable, EJL—esophagojejunostomy leak; HIPEC—hyperthermic intraperitonal chemotherapy, TG—-total gastrectomy, PG—proximal gastrectomy, DTR—double tract reconstruction. The statistically significant results are marked in bold. 
Table 3. Comparison of CCI values depending on demographic, clinical and pathological factors.

\begin{tabular}{|c|c|c|}
\hline Variable & CCI Me (25-75th Percentile) & $p$ \\
\hline \multicolumn{3}{|l|}{ Sex } \\
\hline Male & $0(0-20.9)$ & 0.4341 \\
\hline Female & $0(0-33.7)$ & \\
\hline \multicolumn{3}{|l|}{ Age } \\
\hline$<58$ & $0(0-29.6)$ & 0.3485 \\
\hline$\geq 58$ & $0(0-29.6)$ & \\
\hline \multicolumn{3}{|l|}{ Lauren type } \\
\hline Intestinal & $0(0-20.9)$ & \\
\hline Mixed & $10.4(0-50.7)$ & 0.2172 \\
\hline Diffuse & $0(0-25.2)$ & \\
\hline \multicolumn{3}{|l|}{ Grading } \\
\hline G1 & $20.9(5.2-20.9)$ & \\
\hline G2 & $0(0-37.0)$ & 0.9458 \\
\hline G3 & $0(0-29.6)$ & \\
\hline \multicolumn{3}{|c|}{ Neoadjuvant chemotherapy } \\
\hline Yes & $0(0-29.6)$ & 0.5469 \\
\hline No & $0(0-29.6)$ & \\
\hline \multicolumn{3}{|l|}{ pT } \\
\hline T0 & $0(0-10.6)$ & \\
\hline T1a & $0(0-0)$ & \\
\hline $\mathrm{T} 1 \mathrm{~b}$ & $27.3(0-68.8)$ & \\
\hline $\mathrm{T} 2$ & $20.9(0-20.9)$ & 0.1846 \\
\hline $\mathrm{T} 3$ & $0(0-20.9)$ & \\
\hline $\mathrm{T} 4 \mathrm{a}$ & $0(0-20.9)$ & \\
\hline $\mathrm{T} 4 \mathrm{~b}$ & $39.7(0-52.3)$ & \\
\hline \multicolumn{3}{|l|}{$\mathrm{pN}$} \\
\hline No & $0(0-20.9)$ & \\
\hline N1a & $10.4(0-29.6)$ & \\
\hline N2 & $0(0-35)$ & 0.8275 \\
\hline N3a & $0(0-35.9)$ & \\
\hline $\mathrm{N} 3 \mathrm{~b}$ & $20.9(0-52.7)$ & \\
\hline \multicolumn{3}{|l|}{$\mathrm{pM}$} \\
\hline M0 & $0(0-20.9)$ & 0.1820 \\
\hline M1 & $0(0-44.7)$ & \\
\hline \multicolumn{3}{|l|}{ Surgical margin } \\
\hline R0 & $0(0-25)$ & 0.6758 \\
\hline $\mathrm{R} 1$ & $0(0-41)$ & \\
\hline \multicolumn{3}{|c|}{ Reconstruction method } \\
\hline TG (Roux-en-Y) & $0(0-29.60)$ & 0.7206 \\
\hline PG+DTR & $0(0-25.20)$ & \\
\hline \multicolumn{3}{|l|}{ HIPEC } \\
\hline Yes & $31.6(0-54.2)$ & 0.0034 \\
\hline No & $0(0-20.9)$ & \\
\hline \multicolumn{3}{|l|}{ Postoperative EJL } \\
\hline Yes & $79.5(58.2-100)$ & $<0.0001$ \\
\hline No & $0(0.00-20.9)$ & \\
\hline
\end{tabular}

$\mathrm{CCI}$-comprehensive complication index, Me—median, EJL—esophagojejunostomy leak HIPEC—hyperthermic intraperitonal chemotherapy, TG—-total gastrectomy, PG—proximal gastrectomy, DTR—double tract reconstruction. The statistically significant results are marked in bold. 


\section{Discussion}

The present study was undertaken to evaluate the risk factors of EJL and morbidity in patients with advanced GC. The Laurén mixed histotype has been found to be a new tumor-related risk factor for EJL. Additionally, patients with EJL had a significantly higher number of harvested lymph nodes. The risk of postoperative complications has been significantly higher in patients undergoing HIPEC.

The influence of the Laurén histological type of GC on the occurrence of EJL or postoperative complications in GC patients has not been investigated so far. Recent studies from the Far East have shown more aggressive clinical behavior and worse survival in the mixed type, but mainly for early GC $[28,29]$. Even though it seems that the mixed type does not influence the OS when compared to the diffuse type in both early and advanced GC $[28,30]$, mixed type histology has been indicated as a poor prognostic factor [31]. Aggressive biological features of mixed type GC include high Ki-67 proliferation index, and abnormal expression of E-cadherin and vascular endothelial growth factor (VEGF) [32]. Tumor size and depth of infiltration additionally exacerbate the clinical outcome [28]. The present study indicates that mixed type GC was a significant risk factor of the EJL compared to other types. Consequently, it could have affected the risk of more frequent postoperative complications.

As previously mentioned, poor vascular supply has been recognized as a surgery-related risk factor for EJL $[17,18]$. In total and proximal gastrectomy, both right and left cardiac lymph node stations (no.1 and no.2, respectively) are resected [2]. Since lymphadenectomy with at least 15 perigastric nodes, retrieval could result in improved survival [33], an adequate lymph node harvest should be maintained. On the other hand, extensive lymph node dissection in the cardiac region could presumably lead to poor vascularization of the distal esophagus used for the anastomosis, followed by EJL, as shown in our study.

The use of HIPEC in GC has been investigated in both locoregional and metastatic settings [34,35]. Extended gastrectomy combined with peritonectomy and HIPEC may be beneficial to strictly selected patients with oligometastatic peritoneal GC [36,37]. The ongoing phase III RCT's in the West will determine the potential survival benefit of HIPEC in advanced GC $[38,39]$. The present study shows that HIPEC might result in an increased risk of postoperative complications. However, it is not associated with an increased risk of postoperative leak and does not affect OS compared to patients not treated with HIPEC. Chouliaras et al. described that gastrectomy plus HIPEC is associated with significant mortality and morbidity [40]. The study indicated that patients who suffered from an anastomosis leak after HIPEC had a decreased median OS of 1.6 years compared with 3.1 years in the no-leak group. In contrast, Piso et al. reported that anastomosis following total or subtotal gastrectomy with HIPEC is safe when performed in experienced centers [41]. However, the study group included only 11 patients with GC, while esophagojejunostomy was performed in 15 patients. In recently published meta-analyses [42,43], a significantly higher risk for postoperative complications was reported in patients undergoing prophylactic HIPEC for advanced GC without overt peritoneal metastases. The incidence rate of anastomotic leak ranged from 2 to $20 \%$ [43], yet was without statistical significance when compared to surgery alone groups.

In our experience, anastomotic leak after gastrectomy plus HIPEC was one of the least common (3\%) complications, with median CCI of 42.4 , whereas the grade $3-5$ complication rate was $47 \%$ [36]. In the present study, among 22 patients who underwent gastrectomy with HIPEC, only one (4.5\%) suffered from a postoperative leak. In contrast, the multicenter French CYTO-CHIP study showed that anastomotic leak was a common complication $(35 / 162 ; 21.6 \%)$, whereas grade $3-5$ complications occurred with similar frequency of $53.7 \%$ [37].

There are several limitations to the study. Due to the retrospective nature of the study, it cannot specify causation. Due to the relatively small sample size, subgroup stratification analysis might be biased. Moreover, our study was not designed to analyze the impact of EJL on long-term survival. 


\section{Materials and Methods}

After having institutional review board approval (Bioethical Committee of Medical University of Lublin, Ethic Code: KE-0254/297/2018), we collected data from a prospectively maintained database of all patients operated on GC between October 2014 and December 2019 in the Department of Surgical Oncology of the Medical University of Lublin (Poland). The inclusion criteria were gastrectomy with direct end to side anastomosis between the stump of the distal esophagus, and jejunum. Thus, patients in whom total gastrectomy followed by Roux-en-Y esophagojejunostomy or proximal gastrectomy with double-tract reconstruction (DTR) were included. The exclusion criteria were: distal gastrectomy followed by Rydygier, Billroth II or Roux-en-Y anastomosis, proximal gastrectomy with esophagogastrostomy and anti-reflux procedure, bypass procedure or segmental gastrectomy. Some 114 patients were eligible for the analysis. A flow chart of the study with numbers of patient selection is presented in Figure 1.

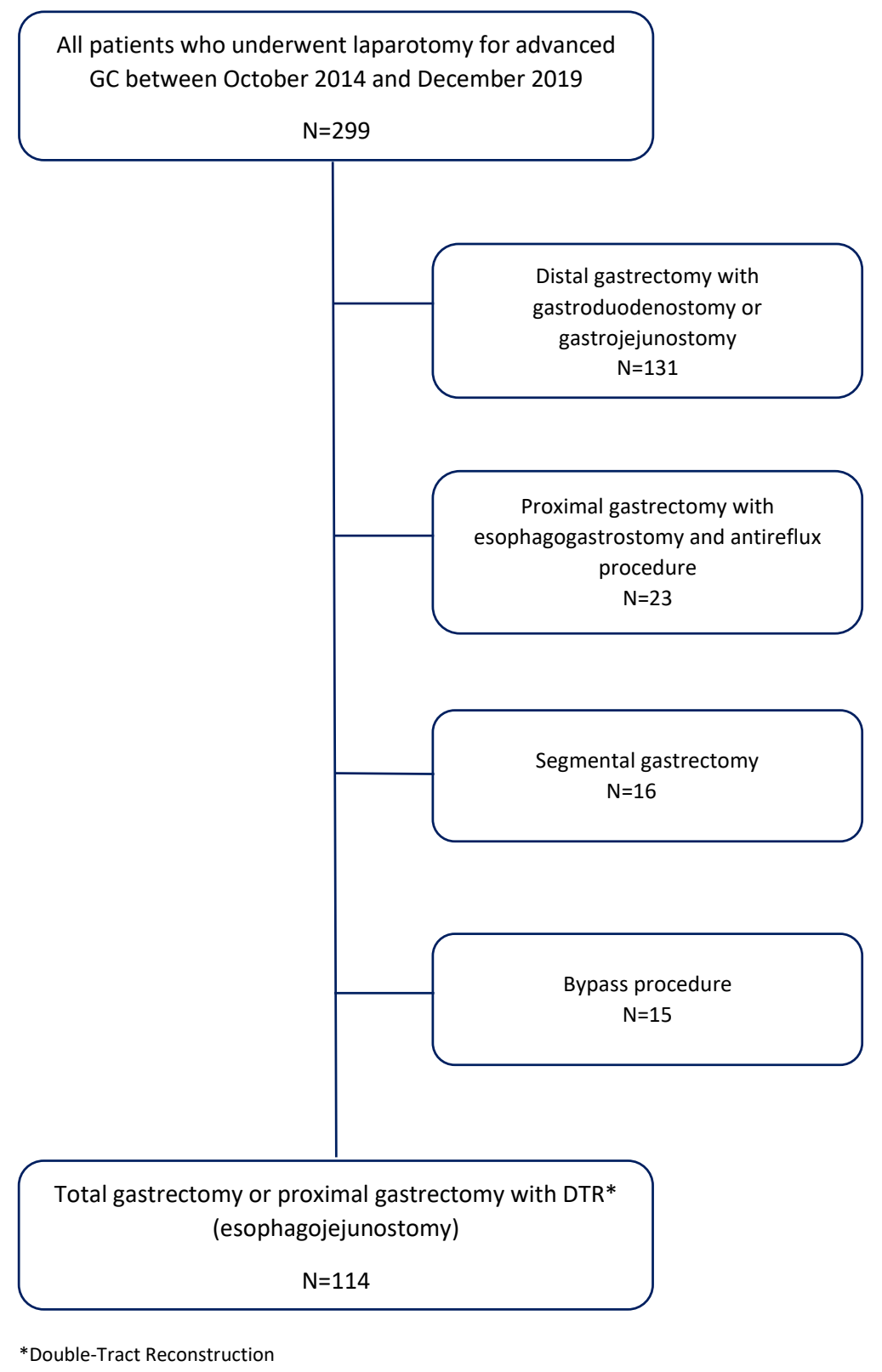

Figure 1. Flow chart of the study. 


\subsection{Neoadjuvant Chemotherapy}

The perioperative EOX regimen consisted of $50 \mathrm{mg} / \mathrm{m}^{2}$ epirubicin and $130 \mathrm{mg} / \mathrm{m}^{2}$ oxaliplatin on day 1 , with $625 \mathrm{mg} / \mathrm{m}^{2}$ capecitabine administered twice daily on days 1-21. The perioperative regimen was repeated 2-3 times every 3 weeks. The FLOT chemotherapy consisted of oxaliplatin, $85 \mathrm{mg} / \mathrm{m}^{2}$; leucovorin, $200 \mathrm{mg} / \mathrm{m}^{2}$; and docetaxel, $50 \mathrm{mg} / \mathrm{m}^{2}$. Each was an intravenous infusion followed by fluorouracil, $2600 \mathrm{mg} / \mathrm{m}^{2}$, as a 24 -hour continuous intravenous infusion on day 1 , repeated every 2 weeks.

\subsection{Laurén Classification}

According to the Laurén histo-prognostic classification, gastric adenocarcinomas are divided into intestinal, diffuse, mixed and indeterminate types [44]. The intestinal type consists of well-formed tubules, whereas the diffuse type is characterized by tumor cells that show poor differentiation and lack of cohesion. The intestinal and diffuse types are pathologically considered as separate entities. When a tumor does not fit into these two types, it is classified as mixed [45]. The histological type was determined in all cases based on the pathological report of the resection specimen.

\subsection{HIPEC}

Indication for the additional use of HIPEC was carried out by the multidisciplinary team, based on a careful assessment of the patients' symptoms and general condition, results of endoscopy, imaging studies (CT scan), pathology subtyping, and staging laparoscopy (unless an exploratory laparotomy has been performed elsewhere). Conversion surgery, including extended gastrectomy, at least D2 lymphadenectomy, and peritonectomy (complete cytoreductive surgery) followed by HIPEC, was performed after systemic chemotherapy for downstaged patients with oligometastatic peritoneal disease, as described previously [36].

\subsection{Esophagojejunostomy Leak}

There is no universally accepted definition of EJL. The one proposed by the UK Surgical Infection Study Group (SISG) in 1991 has not been widely adopted [46]. In this study, postoperative EJL was diagnosed when the patient presented with fever, abdominal pain, leukocytosis, and elevation of C-reactive protein (CRP). The EJL was confirmed by the discovery of drain discharge, during endoscopy examination or by performing water-soluble passage graph or computed tomography (CT) with oral contrast.

\subsection{Morbidity Evaluation}

The Clavien-Dindo classification [47,48] and Comprehensive Complication Index (CCI) [49] scales were used to assess postoperative complications. Complications were prospectively recorded and classified according to the list of the Gastrectomy Complications Consensus Group [50].

\subsection{Statistical Analysis}

All analyses were performed using MedCalc 15.8 (MedCalc Software, Ostend, Belgium). Data were expressed as a percentage (for the categorized variable), mean, standard deviation, median, and range (for continuous variables). We considered $p$ values below 0.05 (two-sided) to be statistically significant. The Spearman correlation test was used to calculate the correlation coefficients. The evaluation of the EJL and postoperative complications according to demographic and clinical (categorized) variables was performed using odds ratio test (multivariate analysis was performed with the use of logistic regression method). The comparison of the values of selected indicators depending on selected demographic and clinical variables was carried out using non-parametric tests (data had a different distribution than normal): ANOVA Kruskal-Wallis (for more than 2 groups) or U-Mann-Whitney (for 2 groups). Overall survival (OS) was defined as the length of time from the date of gastrectomy to the patient's 
death (complete data) or last documented follow-up (censored data). Univariate OS analysis was performed with the use of the Kaplan-Meier estimation method (log-rank), whereas Cox logistic regression models were used in multivariate OS analyses, with statistically significant factors from univariate analysis $(\alpha<0.05)$ as included variables.

\section{Conclusions}

The mixed histological type of GC is a new, tumor-related risk factor for EJL. HIPEC was confirmed to be a risk factor for postoperative complications after gastrectomy.

Author Contributions: Conceptualization, K.R.-P., K.S., W.P.P.; Methodology, K.R.-P., K.S., J.M., W.P.P.; Software, R.M.; Validation, K.R.-P., K.S., R.M. and J.M.; Formal Analysis, K.R.-P., K.S., W.P.P.; Investigation, K.S., K.R.-P., J.M., R.M.; Resources, K.R.-P.; Data Curation, R.M., J.M.,K.R.-P.; Writing - Original Draft Preparation, K.R.-P., K.S., R.M., J.M.; Writing - Review and Editing, K.R.-P., W.P.P.; Visualization, R.M., K.R.-P.; Supervision, W.P.P.; Project Administration, K.R.-P., K.S., J.M., R.M., W.P.P. All authors have read and agreed to the published version of the manuscript.

Funding: This research received no external funding.

Acknowledgments: Authors would like to thank J. Jan B. van Lanschot (Department of Surgery, Erasmus MC, Rotterdam, The Netherlands) for critical review of the manuscript.

Conflicts of Interest: All authors declare no conflict of interest.

\section{References}

1. Bray, F.; Ferlay, J.; Soerjomataram, I.; Siegel, R.L.; Torre, L.A.; Jemal, A. Global cancer statistics 2018: GLOBOCAN estimates of incidence and mortality worldwide for 36 cancers in 185 countries. CA Cancer J. Clin. 2018, 68, 394-424. [CrossRef] [PubMed]

2. Japanese Gastric Cancer Association. Japanese gastric cancer treatment guidelines 2018 (5th edition). Gastric Cancer 2020, 1-21. [CrossRef]

3. Colquhoun, A.; Arnold, M.; Ferlay, J.; Goodman, K.J.; Forman, D.; Soerjomataram, I. Global patterns of cardia and non-cardia gastric cancer incidence in 2012. Gut 2015, 64, 1881-1888. [CrossRef] [PubMed]

4. Cislo, M.; Filip, A.A.; Arnold Offerhaus, G.J.; Cisel, B.; Rawicz-Pruszynski, K.; Skierucha, M.; Polkowski, W.P. Distinct molecular subtypes of gastric cancer: From Lauren to molecular pathology. Oncotarget 2018, 9, 19427-19442. [CrossRef]

5. Smyth, E.C.; Verheij, M.; Allum, W.; Cunningham, D.; Cervantes, A.; Arnold, D.; Committee, E.G. Gastric cancer: ESMO Clinical Practice Guidelines for diagnosis, treatment and follow-up. Ann. Oncol. 2016, 27 (Suppl. S5), v38-v49. [CrossRef]

6. Ajani, J.A.; D'Amico, T.A.; Almhanna, K.; Bentrem, D.J.; Chao, J.; Das, P.; Denlinger, C.S.; Fanta, P.; Farjah, F.; Fuchs, C.S.; et al. Gastric Cancer, Version 3.2016, NCCN Clinical Practice Guidelines in Oncology. J. Natl. Compr. Cancer Netw. 2016, 14, 1286-1312. [CrossRef]

7. Cunningham, D.; Allum, W.H.; Stenning, S.P.; Thompson, J.N.; Van de Velde, C.J.; Nicolson, M.; Scarffe, J.H.; Lofts, F.J.; Falk, S.J.; Iveson, T.J.; et al. Perioperative chemotherapy versus surgery alone for resectable gastroesophageal cancer. N. Engl. J. Med. 2006, 355, 11-20. [CrossRef]

8. Al-Batran, S.E.; Homann, N.; Pauligk, C.; Illerhaus, G.; Martens, U.M.; Stoehlmacher, J.; Schmalenberg, H.; Luley, K.B.; Prasnikar, N.; Egger, M.; et al. Effect of Neoadjuvant Chemotherapy Followed by Surgical Resection on Survival in Patients with Limited Metastatic Gastric or Gastroesophageal Junction Cancer: The AIO-FLOT3 Trial. JAMA Oncol. 2017, 3, 1237-1244. [CrossRef] [PubMed]

9. Haskins, I.N.; Kroh, M.D.; Amdur, R.L.; Ponksy, J.L.; Rodriguez, J.H.; Vaziri, K. The Effect of Neoadjuvant Chemoradiation on Anastomotic Leak and Additional30-Day Morbidity and Mortality in Patients Undergoing Total Gastrectomy for Gastric Cancer. J. Gastrointest. Surg. 2017, 21, 1577-1583. [CrossRef] [PubMed]

10. Claassen, Y.H.M.; Hartgrink, H.H.; Dikken, J.L.; de Steur, W.O.; van Sandick, J.W.; van Grieken, N.C.T.; Cats, A.; Trip, A.K.; Jansen, E.P.M.; Meershoek-Klein Kranenbarg, W.M.; et al. Surgical morbidity and mortality after neoadjuvant chemotherapy in the CRITICS gastric cancer trial. Eur. J. Surg. Oncol. 2018, 44, 613-619. [CrossRef] [PubMed] 
11. Yoshida, K.; Yamaguchi, K.; Okumura, N.; Tanahashi, T.; Kodera, Y. Is conversion therapy possible in stage IV gastric cancer: The proposal of new biological categories of classification. Gastric Cancer 2016, 19, 329-338. [CrossRef] [PubMed]

12. Nakamura, M.; Ojima, T.; Nakamori, M.; Katsuda, M.; Tsuji, T.; Hayata, K.; Kato, T.; Yamaue, H. Conversion Surgery for Gastric Cancer with Peritoneal Metastasis Based on the Diagnosis of Second-Look Staging Laparoscopy. J. Gastrointest. Surg. 2019, 23, 1758-1766. [CrossRef] [PubMed]

13. Japanese Gastric Cancer Association. Japanese gastric cancer treatment guidelines 2014 (ver. 4). Gastric Cancer 2017, 20, 1-19. [CrossRef]

14. Yi, H.W.; Kim, S.M.; Kim, S.H.; Shim, J.H.; Choi, M.G.; Lee, J.H.; Noh, J.H.; Sohn, T.S.; Bae, J.M.; Kim, S. Complications leading reoperation after gastrectomy in patients with gastric cancer: Frequency, type, and potential causes. J. Gastric Cancer 2013, 13, 242-246. [CrossRef] [PubMed]

15. Deguchi, Y.; Fukagawa, T.; Morita, S.; Ohashi, M.; Saka, M.; Katai, H. Identification of risk factors for esophagojejunal anastomotic leakage after gastric surgery. World J. Surg. 2012, 36, 1617-1622. [CrossRef] [PubMed]

16. Messager, M.; Warlaumont, M.; Renaud, F.; Marin, H.; Branche, J.; Piessen, G.; Mariette, C. Recent improvements in the management of esophageal anastomotic leak after surgery for cancer. Eur. J. Surg. Oncol. 2017, 43, 258-269. [CrossRef]

17. Gong, W.; Li, J. Combat with esophagojejunal anastomotic leakage after total gastrectomy for gastric cancer: A critical review of the literature. Int. J. Surg. 2017, 47, 18-24. [CrossRef]

18. Makuuchi, R.; Irino, T.; Tanizawa, Y.; Bando, E.; Kawamura, T.; Terashima, M. Esophagojejunal anastomotic leakage following gastrectomy for gastric cancer. Surg. Today 2019, 49, 187-196. [CrossRef]

19. Kim, S.H.; Son, S.Y.; Park, Y.S.; Ahn, S.H.; Park, D.J.; Kim, H.H. Risk Factors for Anastomotic Leakage: A Retrospective Cohort Study in a Single Gastric Surgical Unit. J. Gastric Cancer 2015, 15, 167-175. [CrossRef]

20. Girard, E.; Messager, M.; Sauvanet, A.; Benoist, S.; Piessen, G.; Mabrut, J.Y.; Mariette, C. Anastomotic leakage after gastrointestinal surgery: Diagnosis and management. J. Visc. Surg. 2014, 151, 441-450. [CrossRef]

21. Schietroma, M.; Cecilia, E.M.; Carlei, F.; Sista, F.; De Santis, G.; Piccione, F.; Amicucci, G. Prevention of anastomotic leakage after total gastrectomy with perioperative supplemental oxygen administration: A prospective randomized, double-blind, controlled, single-center trial. Ann. Surg. Oncol. 2013, 20, 1584-1590. [CrossRef] [PubMed]

22. Migita, K.; Takayama, T.; Matsumoto, S.; Wakatsuki, K.; Enomoto, K.; Tanaka, T.; Ito, M.; Nakajima, Y. Risk factors for esophagojejunal anastomotic leakage after elective gastrectomy for gastric cancer. J. Gastrointest. Surg. 2012, 16, 1659-1665. [CrossRef]

23. Takeuchi, M.; Ishii, K.; Seki, H.; Yasui, N.; Sakata, M.; Shimada, A.; Matsumoto, H. Excessive visceral fat area as a risk factor for early postoperative complications of total gastrectomy for gastric cancer: A retrospective cohort study. BMC Surg. 2016, 16, 54. [CrossRef] [PubMed]

24. Tonouchi, H.; Mohri, Y.; Tanaka, K.; Ohi, M.; Kobayashi, M.; Yamakado, K.; Kusunoki, M. Diagnostic sensitivity of contrast swallow for leakage after gastric resection. World J. Surg. 2007, 31, 128-131. [CrossRef] [PubMed]

25. Sugisawa, N.; Tokunaga, M.; Tanizawa, Y.; Bando, E.; Kawamura, T.; Terashima, M. Intra-abdominal infectious complications following gastrectomy in patients with excessive visceral fat. Gastric Cancer 2012, 15, 206-212. [CrossRef] [PubMed]

26. Marano, L.; Porfidia, R.; Pezzella, M.; Grassia, M.; Petrillo, M.; Esposito, G.; Braccio, B.; Gallo, P.; Boccardi, V.; Cosenza, A.; et al. Clinical and immunological impact of early postoperative enteral immunonutrition after total gastrectomy in gastric cancer patients: A prospective randomized study. Ann. Surg. Oncol. 2013, 20, 3912-3918. [CrossRef] [PubMed]

27. Kang, K.C.; Cho, G.S.; Han, S.U.; Kim, W.; Kim, H.H.; Kim, M.C.; Hyung, W.J.; Ryu, S.Y.; Ryu, S.W.; Lee, H.J.; et al. Comparison of Billroth I and Billroth II reconstructions after laparoscopy-assisted distal gastrectomy: A retrospective analysis of large-scale multicenter results from Korea. Surg. Endosc. 2011, 25, 1953-1961. [CrossRef]

28. Pyo, J.H.; Lee, H.; Min, B.H.; Lee, J.H.; Choi, M.G.; Lee, J.H.; Sohn, T.S.; Bae, J.M.; Kim, K.M.; Yeon, S.; et al. Early gastric cancer with a mixed-type Lauren classification is more aggressive and exhibits greater lymph node metastasis. J. Gastroenterol. 2017, 52, 594-601. [CrossRef] 
29. Komatsu, S.; Ichikawa, D.; Miyamae, M.; Shimizu, H.; Konishi, H.; Shiozaki, A.; Fujiwara, H.; Okamoto, K.; Kishimoto, M.; Otsuji, E. Histological mixed-type as an independent prognostic factor in stage I gastric carcinoma. World J. Gastroenterol. 2015, 21, 549-555. [CrossRef]

30. Zheng, H.C.; Li, X.H.; Hara, T.; Masuda, S.; Yang, X.H.; Guan, Y.F.; Takano, Y. Mixed-type gastric carcinomas exhibit more aggressive features and indicate the histogenesis of carcinomas. Virchows Arch. 2008, 452, 525-534. [CrossRef]

31. Ikari, N.; Taniguchi, K.; Serizawa, A.; Yamada, T.; Yamamoto, M.; Furukawa, T. A primary tumor of mixed histological type is a novel poor prognostic factor for patients undergoing resection of liver metastasis from gastric cancer. J. Hepato-Biliary-Pancreat. Sci. 2017, 24, 281-288. [CrossRef] [PubMed]

32. Zhao, B.; Huang, R.; Lu, H.; Mei, D.; Bao, S.; Xu, H.; Huang, B. Risk of lymph node metastasis and prognostic outcome in early gastric cancer patients with mixed histologic type. Curr. Probl. Cancer 2020, 100579, in press. [CrossRef] [PubMed]

33. Ye, J.; Ren, Y.; Dai, W.; Chen, J.; Cai, S.; Tan, M.; He, Y.; Yuan, Y. Does Lymphadenectomy with at Least 15 Perigastric Lymph Nodes Retrieval Promise an Improved Survival for Gastric Cancer: A Retrospective Cohort Study in Southern China. J. Cancer 2019, 10, 1444-1452. [CrossRef] [PubMed]

34. Coccolini, F.; Cotte, E.; Glehen, O.; Lotti, M.; Poiasina, E.; Catena, F.; Yonemura, Y.; Ansaloni, L. Intraperitoneal chemotherapy in advanced gastric cancer. Meta-analysis of randomized trials. Eur. J. Surg. Oncol. 2014, 40, 12-26. [CrossRef]

35. Newhook, T.E.; Agnes, A.; Blum, M.; Estrella, J.S.; Das, P.; Ho, L.; Ajani, J.A.; Minsky, B.D.; Mansfield, P.; Badgwell, B.D. Laparoscopic Hyperthermic Intraperitoneal Chemotherapy is Safe for Patients with Peritoneal Metastases from Gastric Cancer and May Lead to Gastrectomy. Ann. Surg. Oncol. 2019, 26, 1394-1400. [CrossRef]

36. Mielko, J.; Rawicz-Pruszynski, K.; Skorzewska, M.; Cisel, B.; Pikula, A.; Kwietniewska, M.; Geca, K.; Sedlak, K.; Kurylcio, A.; Polkowski, W.P. Conversion Surgery with HIPEC for Peritoneal Oligometastatic Gastric Cancer. Cancers (Basel) 2019, 11, 1715. [CrossRef]

37. Bonnot, P.E.; Piessen, G.; Kepenekian, V.; Decullier, E.; Pocard, M.; Meunier, B.; Bereder, J.M.; Abboud, K.; Marchal, F.; Quenet, F.; et al. Cytoreductive Surgery with or Without Hyperthermic Intraperitoneal Chemotherapy for Gastric Cancer with Peritoneal Metastases (CYTO-CHIP study): A Propensity Score Analysis. J. Clin. Oncol. 2019, 37, 2028-2040. [CrossRef]

38. Koemans, W.J.; van der Kaaij, R.T.; Boot, H.; Buffart, T.; Veenhof, A.; Hartemink, K.J.; Grootscholten, C.; Snaebjornsson, P.; Retel, V.P.; van Tinteren, H.; et al. Cytoreductive surgery and hyperthermic intraperitoneal chemotherapy versus palliative systemic chemotherapy in stomach cancer patients with peritoneal dissemination, the study protocol of a multicentre randomised controlled trial (PERISCOPE II). BMC Cancer 2019, 19, 420. [CrossRef]

39. Glehen, O.; Passot, G.; Villeneuve, L.; Vaudoyer, D.; Bin-Dorel, S.; Boschetti, G.; Piaton, E.; Garofalo, A. GASTRICHIP: D2 resection and hyperthermic intraperitoneal chemotherapy in locally advanced gastric carcinoma: A randomized and multicenter phase III study. BMC Cancer 2014, 14, 183. [CrossRef]

40. Chouliaras, K.; Levine, E.A.; Fino, N.; Shen, P.; Votanopoulos, K.I. Prognostic Factors and Significance of Gastrointestinal Leak After Cytoreductive Surgery (CRS) with Heated Intraperitoneal Chemotherapy (HIPEC). Ann. Surg. Oncol. 2017, 24, 890-897. [CrossRef]

41. Piso, P.; Slowik, P.; Popp, F.; Dahlke, M.H.; Glockzin, G.; Schlitt, H.J. Safety of gastric resections during cytoreductive surgery and hyperthermic intraperitoneal chemotherapy for peritoneal carcinomatosis. Ann. Surg. Oncol. 2009, 16, 2188-2194. [CrossRef] [PubMed]

42. Desiderio, J.; Chao, J.; Melstrom, L.; Warner, S.; Tozzi, F.; Fong, Y.; Parisi, A.; Woo, Y. The 30-year experience-A meta-analysis of randomised and high-quality non-randomised studies of hyperthermic intraperitoneal chemotherapy in the treatment of gastric cancer. Eur. J. Cancer 2017, 79, 1-14. [CrossRef] [PubMed]

43. Brenkman, H.J.F.; Paeva, M.; van Hillegersberg, R.; Ruurda, J.P.; Haj Mohammad, N. Prophylactic Hyperthermic Intraperitoneal Chemotherapy (HIPEC) for Gastric Cancer-A Systematic Review. J. Clin. Med. 2019, 8, 1685. [CrossRef] [PubMed]

44. Lauren, P. The Two Histological Main Types of Gastric Carcinoma: Diffuse and So-Called Intestinal-Type Carcinoma. An Attempt at a Histo-Clinical Classification. Acta Pathol. Microbiol. Scand. 1965, 64, 31-49. [CrossRef] 
45. Polkowski, W.; van Sandick, J.W.; Offerhaus, G.J.; ten Kate, F.J.; Mulder, J.; Obertop, H.; van Lanschot, J.J. Prognostic value of Lauren classification and c-erbB-2 oncogene overexpression in adenocarcinoma of the esophagus and gastroesophageal junction. Ann. Surg. Oncol. 1999, 6, 290-297. [CrossRef] [PubMed]

46. Bruce, J.; Krukowski, Z.H.; Al-Khairy, G.; Russell, E.M.; Park, K.G. Systematic review of the definition and measurement of anastomotic leak after gastrointestinal surgery. Br. J. Surg. 2001, 88, 1157-1168. [CrossRef]

47. Dindo, D.; Demartines, N.; Clavien, P.A. Classification of surgical complications: A new proposal with evaluation in a cohort of 6336 patients and results of a survey. Ann. Surg. 2004, 240, 205-213. [CrossRef]

48. Slankamenac, K.; Graf, R.; Barkun, J.; Puhan, M.A.; Clavien, P.A. The comprehensive complication index: A novel continuous scale to measure surgical morbidity. Ann. Surg. 2013, 258, 1-7. [CrossRef]

49. Clavien, P.A.; Vetter, D.; Staiger, R.D.; Slankamenac, K.; Mehra, T.; Graf, R.; Puhan, M.A. The Comprehensive Complication Index (CCI(R)): Added Value and Clinical Perspectives 3 Years "Down the Line". Ann. Surg. 2017, 265, 1045-1050. [CrossRef]

50. Baiocchi, G.L.; Giacopuzzi, S.; Marrelli, D.; Reim, D.; Piessen, G.; Matos da Costa, P.; Reynolds, J.V.; Meyer, H.J.; Morgagni, P.; Gockel, I.; et al. International consensus on a complications list after gastrectomy for cancer. Gastric Cancer 2019, 22, 172-189. [CrossRef]

(C) 2020 by the authors. Licensee MDPI, Basel, Switzerland. This article is an open access article distributed under the terms and conditions of the Creative Commons Attribution (CC BY) license (http://creativecommons.org/licenses/by/4.0/). 